\title{
A Study of the Speech of Eight Bilingual Children of the Same Family
}

\author{
Madorah E. SMith
}

I $\mathrm{N}$ A study of height and weight in three generations, use was made of the diary records kept by Mrs. F. M. Smith of the development of her eight children (1). These records also contained considerable data relative to the learning of language by the children. As all of the children were born in China and,--except for one year in America when their parents were on furlough,--lived there until the youngest child was almost twenty months old, during which time they were exposed to and used two languages, it seemed worth while to study the records carefully to see if they would throw any light on the linguistic development of bilingual children.

These records had been kept from the time of the birth of the eldest child until after the removal of the family to America; but unfortunately are rather scanty before the eldest child's third birthday and after the move to America. The portions of the record relating to speech consist of comments on the children's progress, lists of words known at about a year old, age of first real words used, and quotations of the children's remarks and questions that for different reasons interested the mother and seemed worthwhile recording. The quotations listed before the children were four-and-a-half years old numbered about four hundred and fifty sentences and almost twenty-five hundred words. This made possible a numerical analysis of the sentences at different age levels. As there was no consistency in recording sentences other than the interest aroused by the child's remarks and the mother's opportunity and leisure to do so, the assumption is that the samples are of the child's best attempts and the data are not therefore comparable to other studies where the records have been made more systematically. However it is possible to compare one child with another as the selection of samples was subject to the same factors for the different children. Such comparisons make it possible to consider the effect of certain factors which affected the children differently; for the ages of the children at the time of furlough and removal to America varied and there was a difference the mother states in her own use of Chinese with the older and younger children.

The children while in China heard Chinese always from their native nurses, the other servants and from practically all the Chinese, whether children or adult, with whom they came in contact. They heard English almost entirely from all their adult and child white acquaintances, it was the 
language preferred for use among themselves after differentiation between the two languages had occurred; and, in the case of the older children, was the language primarily spoken to them by their parents. But in the case of the younger children, the mother left more of their care to the native nurses while she engaged in mission work and the instruction of the older children. She and the father also used Chinese much more in speaking to the children after their return from furlough. It may be seen therefore that there was a difference in the source of the two languages as heard by the older and the younger children; for the former, the two sources were quite distinct, English from all the whites in their environment and Chinese from all the natives in their environment; while for the latter there was no pure source of English as their parents used either language in speaking to them and there were always one or two children a little older who were still somewhat confused in their use of the two languages. This difference might well lead to increasing the infant's difficulty in learning to distinguish English and Chinese.

In order to make the analysis of the records as objective as possible, the sentences were analyzed according to 5 criteria; sentence length, number of errors per hundred words, number of inflected forms of English words in proportion to the total number of English words used, the percentage of mixed sentences, by which is meant those sentences containing words other than proper nouns from both languages, and finally the percentage of Chinese words used. The material was separated according to the age of the child at time of record, all sentences spoken between the ages of 21 months 0 days and 26 months 29 days being counted as spoken at 24 months and so on for each six-month interval. In order to isolate the factors operating on the children to a different extent, the material was considered separately for the three oldest and five youngest children and also for each of the three children who moved from a bilingual environment to a monolingual environment or vice versa before they were past three years old.

Sentence length and number of errors per hundred words have been used in previous studies $(2,3,4,6)$ as criteria of progress in speech; and give consistent results in the present analysis, even though the samples when so subdivided are small. Sentence length increases regularly with age for each child or group separately studied and the number of errors per hundred words shows a decrease at each age level in the larger groups and at only one level in each of three of the remaining four groupings is there an increase instead of decrease with age. The increase is probably due to the smallness of the samplings. These 2 criteria treated Chinese and English words, sentences and errors exactly the same.

The third criterion that of ability to use correctly inflected forms also gives quite consistent results after two years old. It is not a very satisfactory measure especially with small samples at that age as the baby's frequent use of a few words learned in an inflected rather than a root form, e.g., "gone" hardly indicate knowledge of the use of inflections and yet by the method of count- 
ing used would give the child a score. Chinese inflections are so different that they were considered separately. There -was no progress shown in such use by a comparable measure but the Chinese samples were too small when subdivided by age to be considered except in the case of the younger boys for whom percentages calculated for their Chinese words as had been for the English words gave scores of 8,6 and 8 per cent at eighteen, twenty-four and thirty months old respectively.

The percentage of mixed sentences is a useful measure of the confusion of the children between the two languages and shows regular decrease with age. The proportion of Chinese words at the earlier ages reflects the child's comparative knowledge of the two languages but at the later ages it measures rather the proportion of Chinese words still used when the child was trying to speak English for there is only one sentence primarily in Chinese recorded as spoken after a child's third birthday. This probably reflects both the mother's preference in keeping her records in English and the children's tendency to use English in speaking to their mother.

Table 1 gives the results of this numerical analysis. The mother's comments agree in every case with it. Thus she reports M.'s slow progress in speech before her second birthday, that E. whose record is included with the younger boys was by far the slowest of all her children in learning to talk, and remarks on the high percentage of Chinese used by the younger children during their second and third years.

The order of birth of the children was first the two elder daughters, next
J., then $M$. then the three younger boys, of whom $\mathrm{E}$. was the last and then the youngest girl $\mathrm{H}$.

Considering the factors that affected the children differently, the first comparison may be made between the older and younger children. It will be noted that at every age level the older children excel the younger children by all criteria; with one exception, inflections at two years. They use longer sentences, make fewer errors, make greater use of inflections, and use fewer mixed sentences except at three-and-ahalf years where very few are used. The average age of end of true confusion is earlier for them also although the age of last mixed sentence is about the same. But these last mixed sentences hardly show confusion of the two languages as the earlier mixed sentences do for with but one exception (E.'s), each contains but one Chinese word which are either words for which there is no true English equivalent or words which, for some special reason, the children had been taught to use instead of the corresponding English word. Words of the first class occurring in these last sentences are "meimei" or "younger sister" and "kookoo" or "elder brother"; of the second class are "du-bi" or belly "sz-poo" or diaper. The children were encouraged to use Chinese words to refer to portions of anatomy, calls of nature and articles of clothing tabooed in polite conversation in English in the nineties. The other last word "din-ts" or quilt was currently used in the nursery to distinguish certain small crib pads from the regular bed quilts. Such mixed sentences containing only such words are of a very different type from E.'s 
TABLE 1

Numerical analysis of the speech development of the bilingual children from the age of one to four years

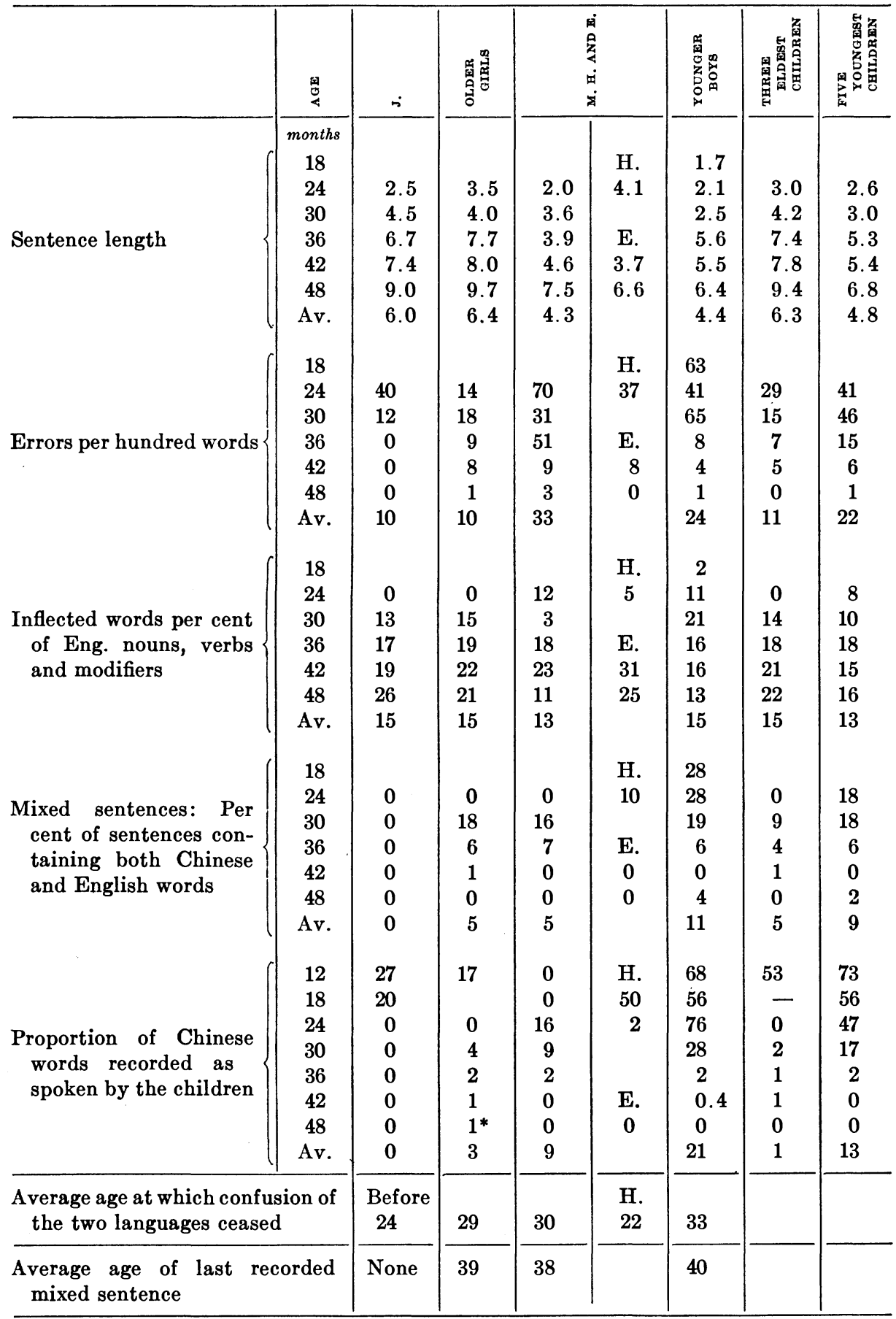

Averages do not include data below the age of 24 months.

* The Chinese words were proper nouns which could not be given in English. 
sentence recorded as spoken at 35 months referring to the snow, (a rarity for him and for which he knew no word) "Jingming's bah sand makes my kyouh t'ung" which translated would read "God's white sand makes my feet hurt." The order is Chinese, the words about half English and half Chinese and the English inflection is attached to a Chinese noun. Is it any wonder that "Grandma does not understand much that E. says" when he visited her in America at 38 months although he was recorded as speaking better English and forgetting Chinese by 39 months old?

This superiority of the older children is not accompanied by any compensating superiority of Chinese on the part of the younger children for all the criteria but the one showing least difference take the Chinese as well as the English into consideration. We may therefore conclude that the confusion of source of languages does probably make learning to speak more difficult for a bilingual child than if the sources are reasonably distinct.

Considering next the effect of removal from a bilingual to a monolingual environment. J., the oldest boy and $\mathrm{H}$. the youngest girl were both so removed at about 20 months old. Both of them had made considerable progress in speech by that time, the record stating that $J$. at 18 months was talking a good deal and that $\mathrm{H}$. at 14 months was talking a good deal in Chinese and using short sentences at 19 months. She had begun to talk the earliest of all the children using six words at eight months and combining two words into her first sentence at nine months. Within two months after leaving China, she was beginning to pick up English and using less Chinese. In neither case was there a record of any mixed sentence after the children's second birthdays. At that date, $\mathrm{H}$. was taken from her family for a two months visit to an aunt after which she no longer used any Chinese. J. however heard it occasionally in his family during the year of furlough and had no difficulty in recovering his Chinese upon return there. H.'s record at two years covering as it does all sentences used from 21 to 27 months covers this period of forgetting and her transition from bilingualism to monolingualism. Her record is given separately therefore as well as included in the record of the five youngest. Unfortunately after that period there is only a single sentence quoted. Dividing her two-year record into two parts by the date of her leaving for the visit to her aunt we find for the first interval a sentence length of 3.1, error index of 62 , and a single use of inflection, that of the possessive sign; and for the latter period a sentence length of 5.0, error index of 20 and the same use of inflections. Her progress as she became adjusted to the monolingual environment was remarkable. These children do not show the difficulty that Mary and Avis Ann and a third infant reported to me (5) did when they underwent a similar move but they were younger and had not made the same start at learning to talk that $J$. and H. had.

The early speed of acquisition of words by the children, the fact that the average of the children's first use of words was ten months and in this respect the younger children were 
ahead of the older (they first used a word at an average age of ten months and the oldest three at eleven months) suggest that the handicap of bilingualism is not felt at this stage but a little later and it is when the child is about eighteen months old that comments on slowness of further progress occur in the records of those who seem to be most handicapped.

$M$. was moved from China to America at a few weeks old and started learning to talk in America. At 13 months she used five English words. The next month the family returned to China and her exposure to bilingualism began. Her record shows relatively slow progress and the mother comments upon it. Finally at 19 months she remarks that $M$. has picked up a few Chinese words and at 21 months she begins to improve, "learning a new word almost every day." At two years she does not show any mixed sentences but a low per cent of such sentences is inevitable when the child is still using many one-word sentences as it is necessary that a sentence consists of at least two words before it can contain words from two languages. The transfer from a monolingual environment to a bilingual environment may be more confusing to an infant than the reverse and it is also noted that $M$. was younger than the two who made the reverse change.

E. is another child who had not mastered speech when the family moved to America. After the decision to leave China had been made, the mother states that she made a special effort to speak Chinese more than ever to the younger children. As a result (?) E. was the oldest of the children to con- tinue his confusion of the two languages. He had been in America nearly three months before the record of his forgetting Chinese occurs. At 42 months nearly half a year after leaving China his sentences are 3.7 words in length, error index is 31 and use of inflections occurs in only 8 per cent of the words, the poorest record of all the children. Were it not for his previous low record and the slight disturbance caused the other two children moving to America at an earlier age and the additional fact that the younger of the two oldest girls who was only a little older than he during the furlough year in America shows no effect of the change, we might consider his slowness due to the change. It would appear more likely due in part, at least, to the same cause that affected the other younger boys, namely the confusion of source of English and Chinese. He had made considerable gain by four years as shown by the last quotations in his record. He made excellent progress when he started to school and his intelligence rating on the Army Alpha during the World War was A so his early slowness was not due to less intelligence than his siblings.

This analysis suggests that:

1. It is probably better for young bilingual children to receive their two languages from quite separate sources, each adult in the home using always the same language in speaking to them.

2. Change from a monolingual environment to a bilingual one affects a child's speech more than a change in the opposite direction.

3. Such changes are more difficult for an infant of twelve to eighteen 
months than for those who have probably selections of the children's already made more progress in speech. best effort rather than of their average

4. A bilingual environment does not performance, yet the ratio of errors is seem to delay the first use of words, in case of the younger children higher the handicap operating at a later age. than the norms of two and three-year-

5. Although the numerical data can- olds found in a previous study, (6) not be compared with other studies of (two years 36 and three years 15 per children's speech since the samples are 100).

\section{REFERENCES}

(1) Baldwin, Bird T. and Smith, Madorah E.: Physical growth of two generations of one family. J. of Hered., 1925, 16, 243-258.

(2) McCarthy, Dorothea A.: The language development of the pre-school child. Minneapolis, The University of Minnesota Press, 1929.

(3) Nice, Margaret M.: Length of sentences as a criterion of a child's progress in speech. J. Educ. Psychol., 1925, 16, 370-379.
(4) Sмrth, Madorah E.: An investigation of the development of the sentence and the extent of vocabulary in young children. Univ. of Iowa Studies in Child Welfare, 1926, 3, No. 5.

(5) Sмith, Madorah E.: A study of five bilingual children from, the same family. Child Dev., 1931, 2, 184-7.

(6) Smith, Madorah E.: Grammatical errors in the speech of pre-school children. Child Dev., 1933, 4, 183-190. 